\title{
Administration of protegrin peptide IB-367 to prevent endotoxin induced mortality in bile duct ligated rats
}

\author{
A Giacometti, O Cirioni, R Ghiselli, F Mocchegiani, G D'Amato, M Simona Del Prete, \\ F Orlando, W Kamysz, J Lukasiak, V Saba, G Scalise
}

See end of article for authors' affiliations

\section{Correspondence to:} Dr A Giacometti, Clinica delle Malattie Infettive, $\mathrm{c} / \mathrm{o}$ Ospedale Regionale, Via Conca, 60020 Torrette AN, Italy;

anconacmi@interfree.it

Accepted for publication 18 December 2002

\begin{abstract}
Background: Postoperative morbidity in patients with obstructive jaundice remains high because of increased susceptibility to endotoxin and the inflammatory cascade.

Aims: An experimental study was designed to investigate the efficacy of protegrin peptide IB-367, an antimicrobial positively charged peptide, in neutralising Escherichia coli 011 1:B4 lipopolysaccharide (LPS) in bile duct ligated rats.

Methods: Adult male Wistar rats were injected intraperitoneally with $2 \mathrm{mg} / \mathrm{kg} E$ coli 0111 1:B4 LPS one week after sham operation or bile duct ligation (BDL). Six groups were studied: sham with placebo, sham with $120 \mathrm{mg} / \mathrm{kg}$ tazobactam- piperacillin (TZP), sham with $1 \mathrm{mg} / \mathrm{kg} \mathrm{IB-367,} \mathrm{BDL} \mathrm{with} \mathrm{placebo,}$ BDL with $120 \mathrm{mg} / \mathrm{kg}$ TZP, and BDL with $1 \mathrm{mg} / \mathrm{kg} \mathrm{IB-367.}$

Results: Main outcome measures were: endotoxin and tumour necrosis factor $\alpha$ (TNF- $\alpha$ ) concentrations in plasma, evidence of bacterial translocation in blood and peritoneum, and lethality. After LPS, TNF- $\alpha$ plasma levels were significantly higher in BDL rats compared with sham operated animals. IB-367 caused a significant reduction in plasma endotoxin and TNF- $\alpha$ concentrations compared with placebo and TZP treated groups. In contrast, both TZP and IB- 367 significantly reduced bacterial growth compared with saline treatment. Finally, LPS induced $60 \%$ and $55 \%$ lethality in BDL placebo and TZP treated rats and no lethality in sham operated rats, while only IB-367 significantly reduced lethality to $10 \%$.

Conclusions: By virtue of its dual antimicrobial and antiendotoxin properties, IB-367 could be an interesting compound to inhibit bacterial translocation and endotoxin release in obstructive jaundice.
\end{abstract}

$S^{p}$ pontaneous bacterial infections and sepsis have been described in patients with portal hypertension and obstructive jaundice..$^{1-3}$ These infectious episodes account for high morbidity and death rates and, although without apparent source of infection, are caused by Gram negative bacteria normally present in the gut. ${ }^{45}$ The egress of intraluminal intestinal organisms to distant organs, a process termed bacterial translocation (BT), is an attractive hypothesis to explain the high incidence of infections with enteric bacteria in certain condition, which may disrupt the intestinal barrier. $^{26-8}$ In fact, the mucosa of the gastrointestinal tract provides an effective barrier to entry of intestinal bacteria and endotoxin in healthy individuals. ${ }^{19}{ }^{10}$ The pathogenesis of BT is unknown but disturbance of homeostasis between the intestinal microflora and host defence mechanisms such as the mucosal barrier, immunological defence, alteration of the normal low $\mathrm{pH}$ in the stomach, motility disturbances of the digestive tract, and mesenteric ischaemia can lead to BT. ${ }^{129}$ BT may cause secondary infections to normally sterile extraintestinal sites, such as the mesenteric lymph nodes, liver, spleen, kidney, peritoneal cavity, and bloodstream..$^{1-3}$ Furthermore, BT and absorption of the lipopolysaccharide (LPS) associated with cell membranes of Gram negative bacteria, known as endotoxin, may have severe systemic effects and may result in endotoxaemia. $^{211-15}$ It has been demonstrated that endotoxin activates the host effector cells through stimulation of receptors on their surface. ${ }^{16}$ These target cells secrete large quantities of inflammatory cytokines, such as tumour necrosis factor (TNF), interleukin (IL)-1, IL-6, and IL-8, platelet activating factor, arachidonic acid metabolites, erythropoietin, and endothelin. ${ }^{17}{ }^{18}$ LPS is composed of an $O$-polysaccharide chain, a core sugar, and a lipophilic fatty acid: lipid A. Lipid A produces the signal responsible for induction of cytokine genes. ${ }^{16-19}$ Recently it has been shown that biliary obstruction is commonly associated with a systemic inflammatory response and elevated circulating cytokine levels. Interestingly, an important elevation of $\mathrm{C}$ reactive protein levels in cholestatic animals was associated with elevation in serum IL-6 and TNF- $\alpha$ levels. ${ }^{13}$

Many methods have been used to target endotoxin to reduce complications resulting from biliary obstructionexternal or, more recently, internal biliary drainage, monoclonal antibodies to endotoxin, antioxidants, and various anti-inflammatory therapies-but no treatment produced clinically effective results. ${ }^{20} 21$

Antimicrobial peptides are positively charged molecules isolated from a wide variety of animals and plants in which they act as natural defence mechanisms. Most of these molecules, natural or synthetic, are amphipathic and have a broad spectrum of activity against bacteria, fungi, and protozoa. ${ }^{22}$ Among these compounds, protegrins were originally isolated from porcine leucocytes. They are cysteine rich molecules consisting of 16-18 amino acids with multiple arginine residues and two disulphide bonds forming a $\beta$-sheet. ${ }^{24}{ }^{25}$ IB- 367 (RGGLCYCRGRFCVCVGR ${ }_{\text {СоNн2 }}$ ), a synthetic protegrin, demonstrated improved bactericidal and fungicidal activity compared with those of native protegrins. ${ }^{25}{ }^{26}$ The arginine residues make protegrins highly cationic molecules and this property is primarily implicated in the activity against Gram negative bacteria. In fact, polycationic peptides bind to the negatively charged residues of LPS on the outer membrane

Abbreviations: BT, bacterial translocation; LPS, lipopolysaccharide TNF- $\alpha$, tumour necrosis factor $\alpha$; IL, interleukin; TZP tazobactam-piperacillin; BDL, bile duct ligation; CFU, colony forming units. 
by electrostatic interactions involving the negatively charged phosphoryl groups and by hydrophobic interactions involving the acyl chains of lipid A, and so determining the key mechanistic step in the killing of Gram negative organisms. Successively, the peptides can transverse the outer membrane and cause the formation of pores or solubilisation of the inner membrane. ${ }^{22} 2328$ These antimicrobial compounds are receiving increasing attention as they possess antiendotoxin activity also. ${ }^{29-31}$ There is a growing evidence that their ability to bind lipid A plays a role in the defence against infections, as important to the host as antibodies, immune cells, and phagocytes. ${ }^{23}$

The present experimental study was designed to investigate the antimicrobial and antiendotoxin activity of IB-367 in a rat model of obstructive jaundice.

\section{MATERIALS AND METHODS}

\section{Animals}

Adult male Wistar rats weighting 250-300 g were used for all experiments. All animals were housed in individual cages under constant temperature $\left(22^{\circ} \mathrm{C}\right)$ and humidity with a 12 hour light/dark cycle, and had access to chow and water ad libitum throughout the study. The study was approved by the animal research ethics committee of the INRCA IRRCS, University of Ancona, Ancona, Italy.

\section{Reagents}

Endotoxin (Escherichia coli serotype 0111:B4; Sigma-Aldrich Srl, Milan, Italy) was prepared in sterile saline, aliquoted, and stored at $-80^{\circ} \mathrm{C}$ for short periods.

\section{Agents}

IB-367 was synthesised manually (Faculty of Pharmacy, Medical University of Gdansk, Poland) by 9-fluorenylmethoxycarbonyl solid phase chemistry using the protocol described previously. ${ }^{25}$ The peptide was purified by solid phase extraction on Kromasil sorbent (C8, $5 \mu \mathrm{m}, 100 \AA \AA) .{ }^{32}$ The resulting fractions with purity greater than $97-98 \%$ were tested by high pressure liquid chromatography. The peptide was analysed by chemical analysis and matrix assisted laser desorption ionisation mass spectrometry.

IB-367 was dissolved in distilled $\mathrm{H}_{2} \mathrm{O}$ at 20 times the required maximal concentration. Successively, it was diluted in physiological saline. Tazobactam-piperacillin (Wieth Lederle, Aprilia, Italy) was diluted in accordance with the manufacturer's recommendations. Solutions were made fresh on the day of assay.

\section{Experimental design}

Rats were assigned to one of six groups, each containing 20 animals: sham operation with placebo, sham operation with tazobactam-piperacillin (TZP), sham operation with IB-367, bile duct ligation (BDL) with placebo, BDL with TZP, and BDL with IB-367. Rats were anaesthetised at time $t=-7$ days by intramuscular injection of ketamine $30 \mathrm{mg} / \mathrm{kg}$ body weight. The surgical procedures were either a sham operation in which, after opening the abdomen via a $2 \mathrm{~cm}$ midline incision, the bile duct was dissected from surrounding tissues, or BDL, in which the bile duct was prepared free and doubly ligated using 5-0 silk and divided according to the procedure described by Lee. After either operation the abdomen was closed in two layers using 4-0 chromic catgut. All procedures were performed observing strict asepsis. One week later (time 0 ) each animal was injected intraperitoneally with $2.0 \mathrm{mg}$ of Escherichia coli serotype 0111:B4 LPS in a total volume of $500 \mu \mathrm{l}$ of sterile saline. Immediately after injection, the animals in the six groups received intraperitoneally isotonic sodium chloride solution (placebo), $1 \mathrm{mg} / \mathrm{kg}$ IB-367, and $120 \mathrm{mg} / \mathrm{kg}$ TZP, respectively. The animals were returned to individual cages and examined daily. Toxicity was evaluated on the basis of the presence of any drug related adverse effect-that is, local signs of inflammation, anorexia, weight loss, vomiting, diarrhoea, fever, and behavioural alterations. The animals were monitored for the subsequent 48 hours.

\section{Blood sampling procedure}

For blood cultures and determination of endotoxin and TNF- $\alpha$ in plasma, $0.2 \mathrm{ml}$ blood samples were collected from a tail vein into a sterile syringe and transferred to tubes containing ethylenediaminetetraacetic acid tripotassium salt (EDTA-K K $_{3}$.

Blood samples were taken before operation ( $t=-7$ days), before $(\mathrm{t}=0)$ LPS administration, and 2, 6, 24, and 48 hours after injection.

\section{Biochemical assays}

Endotoxin concentrations were measured by the Limulus amoebocyte lysate test (E- TOXATE; Sigma-Aldrich). Plasma samples were serially diluted twofold with sterile endotoxin free water and heat treated for five minutes in a water bath at $75^{\circ} \mathrm{C}$ to destroy inhibitors that can interfere with activation. Endotoxin content was determined as described by the manufacturer. Endotoxin standards $(0,0.015,0.03,0.06$, $0.125,0.25$, and $0.5 \mathrm{EU} / \mathrm{ml}$ ) were tested in each run, and the concentration of endotoxin in the text samples was calculated by comparison with the standard curve.

TNF- $\alpha$ levels were measured with a commercially available solid phase sandwich enzyme linked immunosorbent assay (Nuclear Laser Medicine, Srl, Settala, Italy) according to the protocol supplied by the manufacturer. Standards and samples were incubated with a TNF- $\alpha$ antibody coated 96 well microtitre plate. The wells were washed with buffer and incubated with biotinylated anti-TNF- $\alpha$ antibody conjugated to streptavidin-peroxidase. This was washed away and colour was developed in the presence of chromogen (tetramethylbenzidine) substrate. The intensity of the colour was measured in a MR 700 Microplate Reader (Dynatech Laboratories, Guernsey, UK) by reading absorbance at $450 \mathrm{~nm}$. Results for the samples were compared with the standard curve to determine the amount of TNF- $\alpha$ present. All samples were run in duplicate. The lower limit of sensitivity for TNF- $\alpha$ by this assay was $0.05 \mathrm{ng} / \mathrm{ml}$. The intra-assay and interassay coefficients of variation were $5.8 \%$ and $7.7 \%$, respectively.

\section{Microbiological studies}

To evaluate the presence of BT, bacterial analysis was performed on blood and intra- abdominal fluid obtained under sterile conditions.

Blood samples for aerobic and anaerobic cultures were obtained by aseptic percutaneous transthoracic cardiac puncture from all animals, 48 hours after the end of LPS infusion or at the time of death. Before cardiac puncture, surviving animals were killed with chloroform.

In addition, to perform quantitative bacterial evaluation of intra-abdominal fluid from each animal, $10 \mathrm{ml}$ of sterile saline were injected intraperitoneally and samples of the peritoneal lavage fluid were serially diluted and a $0.1 \mathrm{ml}$ volume of each dilution was spread onto blood agar plates for enumeration of developed colonies. For isolation of anaerobes, specimens were inoculated onto Columbia blood agar plates enriched with hemin and menadione, and incubated in an anaerobic chamber in $80 \% \mathrm{~N}_{2}-10 \% \mathrm{H}_{2}-10 \% \mathrm{CO}_{2}$. The limit of detection was $<1$ $\log _{10}$ colony forming units $(\mathrm{CFU}) / \mathrm{ml}$. Plates were incubated both in air and under anaerobic conditions at $35^{\circ} \mathrm{C}$ for 48 hours.

\section{Statistical analysis}

Survival data were compared by the log rank test. Qualitative results for blood cultures were analysed by the $\chi^{2}$ test, Yates correction, or Fisher's exact test, depending on the sample size. Quantitative evaluation of bacteria in intra-abdominal 
Table 1 Endotoxin levels $(\mathrm{EU} / \mathrm{ml})$ in sham operated rats and bile duct ligated (BDL) rats at different times

\begin{tabular}{lllcccc}
\hline Group $^{\mathrm{a}}$ & -7 days & Time $0^{\mathrm{b}}$ & $2 \mathrm{~h}^{\mathrm{b}}$ & $6 \mathrm{~h}$ & $24 \mathrm{~h}$ & $48 \mathrm{~h}$ \\
\hline Sham placebo & $0.093(0.021)$ & $0.101(0.035)$ & $5030.6(1076.7)$ & $4122.5(1055.2)^{\mathrm{b}}$ & $0.272(0.042)^{\mathrm{b}}$ & $0.115(0.035)^{\mathrm{b}}$ \\
Sham TZP & $0.099(0.013)$ & $0.097(0.029)$ & $4884.3(1003.2)$ & $4633.6(1,015.1)^{\mathrm{b}}$ & $0.259(0.044)^{\mathrm{b}}$ & $0.109(0.032)^{\mathrm{b}}$ \\
Sham IB-367 & $0.090(0.026)$ & $0.096(0.019)$ & $487.3(106.7)$ & $422.9(98.4)^{\mathrm{b}}$ & $0.088(0.027)^{\mathrm{b}}$ & $0.098(0.012)^{\mathrm{b}}$ \\
BDL placebo & $0.096(0.034)$ & $0.357(0.092)^{*}$ & $5871.8(1115.6)$ & $5573.7(1,095.3)^{\mathrm{c}}$ & $0.476(0.089)^{\mathrm{d}}$ & $0.398(0.068)^{\mathrm{e}}$ \\
BDL TZP & $0.090(0.017)$ & $0.331(0.088)^{*}$ & $5699.6(1077.4)$ & $5491.1(1,021.8)^{\mathrm{t}}$ & $0.451(0.094)^{\mathrm{g}}$ & $0.412(0.073)^{\mathrm{h}}$ \\
BDL IB-367 & $0.095(0.028)$ & $0.302(0.104)^{*}$ & $544.5(121.3) \dagger$ & $501.3(98.5)^{\dagger} \dagger$ & $0.279(0.095) \dagger$ & $0.291(0.102)^{\dagger} \dagger$ \\
\hline
\end{tabular}

Results are given as mean (SD).

aTP, tazobactam-piperacillin $120 \mathrm{mg} / \mathrm{kg}$; IB-367 $1 \mathrm{mg} / \mathrm{kg}$.

Each measurement refers to: ${ }^{b} 20$ animals; ${ }^{c} 13$ animals; ${ }^{d}$ seven animals; ${ }^{e}$ six animals; ${ }^{\mathrm{t}} 15$ animals; ${ }^{9} 10$ animals; ${ }^{\mathrm{h}}$ nine animals; ${ }^{i} 18$ animals.

${ }^{*} \mathrm{p}<0.05$ versus sham operated rats.

t $p<0.05$ versus BDL placebo and TZP treated animals.

Table 2 Tumour necrosis factor levels $(\mathrm{ng} / \mathrm{ml})$ in sham operated rats and bile duct ligated (BDL) rats at different times

\begin{tabular}{|c|c|c|c|c|c|c|}
\hline Group $^{a}$ & -7 days & Time $0^{b}$ & $2 \mathrm{~h}^{\mathrm{b}}$ & $6 \mathrm{~h}$ & $24 \mathrm{~h}^{\mathrm{b}}$ & $48 \mathrm{~h}^{\mathrm{b}}$ \\
\hline Sham placebo & $\leqslant 0.05$ & $0.08(0.02)$ & $1.12(0.45)$ & $0.26(0.07)^{b}$ & $\leqslant 0.05^{b}$ & $\leqslant 0.05^{b}$ \\
\hline Sham TZP & $\leqslant 0.05$ & $0.09(0.02)$ & $0.98(0.22)$ & $0.31(0.08)^{b}$ & $\leqslant 0.05^{b}$ & $\leqslant 0.05^{b}$ \\
\hline Sham IB-367 & $\leqslant 0.05$ & $0.07(0.02)$ & $0.43(0.16)$ & $0.13(0.05)^{b}$ & $\leqslant 0.05^{b}$ & $\leqslant 0.05^{b}$ \\
\hline BDL placebo & $\leqslant 0.05$ & $0.12(0.03)$ & $4.65(1.14)$ & $0.91(0.19)^{c}$ & $0.13(0.03)^{d}$ & $0.11(0.02)^{\mathrm{e}}$ \\
\hline BDL TZP & $\leqslant 0.05$ & $0.12(0.03)$ & $4.87(1.39)$ & $0.82(0.21)^{f}$ & $0.14(0.04)^{g}$ & $0.12(0.03)^{\mathrm{h}}$ \\
\hline BDL IB-367 & $\leqslant 0.05$ & $0.09(0.03)$ & $0.78(0.22)$ & $0.18(0.04)^{\text {i* }}$ & $0.06(0.01)^{i *}$ & $0.07(0.02)^{i}$ \\
\hline
\end{tabular}

Results are given as mean $(\mathrm{SD})$

TZP, tazobactam-piperacillin $120 \mathrm{mg} / \mathrm{kg} ; \mathrm{IB}-3671 \mathrm{mg} / \mathrm{kg}$

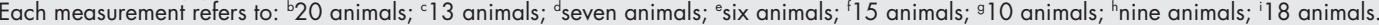

${ }^{*} p<0.05$ versus $B D L$ placebo and TZP treated animals.

fluid cultures are presented as mean (SEM); statistical comparisons between groups were made using analysis of variance (ANOVA). Post hoc comparisons were performed by Bonferroni's test. Plasma endotoxin and TNF- $\alpha$ levels were analysed using the Kruskal-Wallis test; multiple comparisons between groups were performed using the appropriate standard procedure. Each comparison group contained 20 rats. Significance was accepted when $\mathrm{p} \leqslant 0.05$.

\section{RESULTS}

The main outcome measures were: endotoxin and TNF- $\alpha$ concentrations in plasma, evidence of BT, and lethality.

\section{Endotoxin and TNF- $\alpha$ levels}

On $t=-7$ days, endotoxin levels were not significantly different between the groups (table 1 ). However, at $t=0$, one week after operation, there were important changes in endotoxin levels $(0.098(0.01) \mathrm{EU} / \mathrm{ml}$ in all sham rats and 0.330 $(0.07) \mathrm{EU} / \mathrm{ml}$ in all BDL rats, respectively) $(\mathrm{p}<0.001)$.

Two hours after induction of endotoxaemia, endotoxin levels were 5030.6 (1076.7) EU/ml and 5871.8 (1115.6) EU/ml in the sham and BDL placebo groups, respectively. Similar results were observed in the two TZP treated groups. In contrast, IB-367 caused a significant reduction in plasma endotoxin concentration compared with placebo and TZP treated groups (487.3 (106.7) EU/ml and 544.5 (121.3) EU/ml in sham and BDL rats, respectively) $(\mathrm{p}<0.001)$.

Comparable results were found six hours after LPS injection (table 1). At 24 and 48 hours, in all surviving animals, plasma endotoxin concentrations returned towards levels detected before LPS injection $(t=0)$. The lowest values were detected in the sham protegrin treated group (table 1 ).

TNF- $\alpha$ levels in all groups were $\leqslant 0.05 \mathrm{ng} / \mathrm{ml}$ at $\mathrm{t}=-7$ days. Overall, at $\mathrm{t}=0$ there were significant differences $(\mathrm{p}<0.001)$ in TNF- $\alpha$ levels between sham operated and BDL rats $(0.08$ $(0.02) \mathrm{ng} / \mathrm{ml}$ and $0.11(0.03) \mathrm{ng} / \mathrm{ml}$, respectively). Within two hours of induction of endotoxaemia, TNF- $\alpha$ levels reached a peak in all groups, being significantly highest in BDL treated with placebo or TZP, followed by sham treated with placebo or TZP (table 2). IB- 367 achieved a significant reduction in

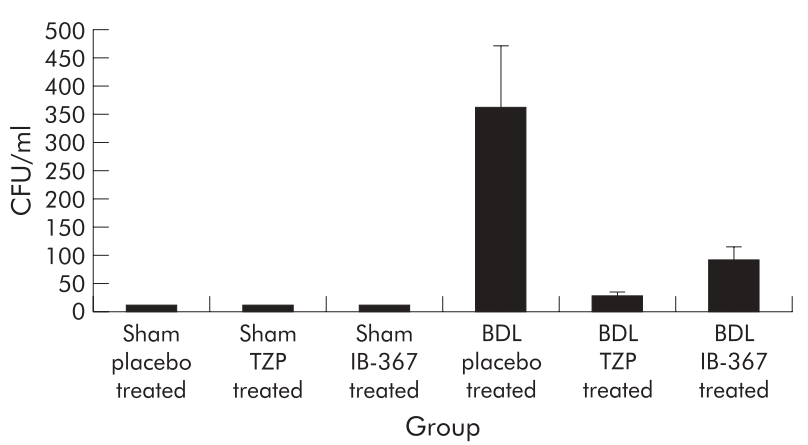

Figure 1 Antimicrobial activities of an intraperitoneal monodose of $120 \mathrm{mg} / \mathrm{kg}$ tazobactam-piperacillin (TZP) and $1 \mathrm{mg} / \mathrm{kg} \mathrm{IB-367} \mathrm{in}$ sham operated and bile duct ligated (BDL) rats. CFU, colony forming units.

plasma TNF- $\alpha$ concentration compared with the four above mentioned groups $(p<0.01)$. In all groups, TNF- $\alpha$ levels returned towards prechallenge concentrations six hours after injection of LPS (table 2).

\section{Bacterial translocation}

Bacteriological evaluation showed no positive blood or intra-abdominal fluid cultures in sham operated animals. In contrast, for the BDL model, blood cultures grew bacteria in $15 \%, 5 \%$, and $10 \%$ of placebo, TZP, and IB-367 treated rats, respectively. Finally, in the BDL model, evidence of bacterial colonisation in peritoneal fluid was demonstrated in $25 \%$, $10 \%$, and $15 \%$ of placebo, TZP, and IB-367 treated rats, respectively. Specifically, for BDL placebo treated rats, quantitative cultures of intra-abdominal fluid demonstrated the highest bacterial numbers, averaging $3.6 \times 10^{2}\left(1.1 \times 10^{2}\right) \mathrm{CFU} / \mathrm{ml}$, while TZP exerted the strongest antibacterial activity producing a mean of $2.5 \times 10^{1}\left(0.7 \times 10^{1}\right) \mathrm{CFU} / \mathrm{ml}$ (fig 1). Gram negative and Gram positive bacteria were simultaneously isolated from more than $70 \%$ of animals. The pathogens isolated from both blood and abdominal fluid were mainly members of the Enterobacteriaceae family, including E coli, Enterobacter spp, 
Table 3 Effect of intraperitoneal monodose of $120 \mathrm{mg} / \mathrm{kg}$ tazobactam-piperacillin (TZP) and $1 \mathrm{mg} / \mathrm{kg} \mathrm{IB-367}$ on mortality in sham operated rats and bile duct ligated (BDL) rats

\begin{tabular}{lllllll}
\hline Time $(h)$ & Sham placebo & Sham TZP & Sham IB-367 & BDL placebo & BDL TZP & BDL IB-367 \\
\hline 0 & 1 & 1 & 1 & 1 & 1 & 1 \\
6 & 1 & 1 & 1 & 0.65 & 0.75 & 0.9 \\
12 & 1 & 1 & 1 & 0.5 & 0.65 & 0.9 \\
24 & 1 & 1 & 1 & 0.35 & 0.5 & 0.9 \\
36 & 1 & 1 & 1 & 0.3 & 0.45 & 0.9 \\
48 & 1 & 1 & 1 & 0.3 & 0.45 & 0.9 \\
\hline
\end{tabular}

Proteus spp, and Gram positive cocci (primarily enterococci). The most frequently isolated anaerobic organisms were Bacteroides spp.

\section{Lethality}

LPS induced $60 \%$ lethality in BDL placebo treated rats and no lethality in sham operated rats. Eleven of 20 TZP treated rats $(55 \%)$ with BDL did not survive past 48 hours. With IB- 367 treatment, lethality was reduced to two of 20 BDL rats (10\%). In addition, among BDL rats, only IB-367 significantly reduced lethality compared with placebo (table 3). Finally, none of the agents showed any toxicity; in fact none of the animals had clinical evidence of drug related adverse effects, such as local signs of inflammation, anorexia, weight loss, vomiting, diarrhoea, fever, or behavioural alterations.

\section{DISCUSSION}

Endotoxaemia is strongly implicated in the complications common to jaundiced patients undergoing surgery. ${ }^{2}$ Endotoxaemia in biliary obstruction is probably the result of disturbance of the homeostatic gut-liver system. In fact, under the influence of various critical illnesses, such as total biliary obstruction, intestinal mucosal integrity is compromised and barrier function can be lost, permitting the passage of indigenous intestinal bacteria and endotoxins into the circulation and organs which are normally sterile, a term which has been coined bacterial translocation (BT). BT may have profound systemic effects, and may result in secondary infections, such as intra-abdominal abscesses, peritonitis, and bacteraemia, as well as endotoxaemia. In addition, endotoxin may increase the permeability of the intestinal mucosa thereby facilitating BT and endotoxin absorption. In this way the gut can become the source of an ongoing septic state in individuals without a defined infectious focus.

The aim of this study was to investigate the effect of IB-367, a new synthetic protegrin, on endotoxin induced mortality in rats that had undergone BDL. The results of the study showed that LPS administration was followed by mortality only in BDL rats. Specifically, although one week after operation there were significant changes in endotoxin levels between sham and BDL rats only, induction of high endotoxaemia in BDL rats resulted in a 48 hour lethality rate of $60 \%, 55 \%$, and $10 \%$ in placebo, TZP, and IB-367 treated animals.

The amount of endotoxin detected in plasma after $E$ coli serotype 0111:B4 LPS administration was higher in placebo treated BDL rats. Previous reports have described that endotoxaemia may be the result not only of increased absorption of endotoxins through disrupted gut barrier but also of decreased capacity of mononuclear cells for inactivating endotoxins. $^{29}$ In contrast, reduction in endotoxaemia and endotoxin induced mortality among IB-367 treated BDL rats, compared with placebo and TZP treated BDL rats, may be not only the result of direct neutralisation of LPS by binding of the lipid A moiety, inhibiting the biological activity of endotoxin, but also of a reduction in the amount of circulating endotoxin available for binding to Kupffer cells and inducing production of cytokines such as TNF- $\alpha$. In fact, intraperitoneal administration of IB-367 immediately after injection of LPS would have directly inactivated the endotoxin, thus preventing its systemic effects.

It has been demonstrated that final plasma TNF- $\alpha$ levels are the result of a fine balance involving the whole mononuclear phagocyte system. In jaundiced animals, peritoneal macrophage function was significantly depressed seven days after BDL. ${ }^{33}$ Nevertheless, it has been demonstrated that the number of Kupffer cells increases during experimental biliary obstruction and it is known that Kupffer cells are unique in certain respects. ${ }^{34}$ In fact, they are strongly activated by bacterial endotoxins and normally in a low grade state of activation because of the small quantities of endotoxins that continually penetrate the intact intestinal mucosa. ${ }^{33}$

The different number and state of activation of Kupffer cells in sham and BDL rats may explain the lethality reported in the last model. We observed that plasma TNF- $\alpha$ levels peaked two hours after exposure to LPS both in jaundiced and sham operated rats but TNF- $\alpha$ secretion in BDL animals exceeded that of sham rats by a factor of approximately 50 . These findings indicate that plasma TNF- $\alpha$, rather than endotoxin levels, are related to lethality.

Finally, the present study confirms that ligation of the bile duct increases the rate of translocation of enteric bacteria, even though this phenomenon did not appear to be directly related to survival, as demonstrated by the high lethality rate in TZP treated BDL rats in spite of the strong antibacterial activity of this compound.

The peculiar ability of antimicrobial peptides, such as IB-367, to inhibit not only bacterial growth but also biological activity of the endotoxin may offer an important opportunity for a new approach in the therapeutic strategies in obstructive jaundice. In fact, they act on Gram negative bacteria by initially binding to their surface polyanionic LPS, followed by self promoted uptake across the outer membrane. By virtue of this affinity for LPS, the cationic peptides operate as antiendotoxin agents and inhibit the production of cytokines such as TNF- $\alpha$ by macrophages stimulated with LPS. ${ }^{28} 2935$

This study has demonstrated that a single intraperitoneal dose of IB-367 produced significant reductions in plasma endotoxin and TNF- $\alpha$ levels compared with levels in the placebo and the TZP treated groups. On the basis of our results, IB-367 may have certain potential advantages. Firstly, the use of single doses of the compound resulted in significant inhibition of bacterial growth compared with that in the placebo groups. In addition, it produced a significant reduction in plasma endotoxin and TNF- $\alpha$ levels compared with those in the TZP treated groups, confirming its double antimicrobial and antiendotoxin activities.

affiliations

A Giacometti, O Cirioni, G D'Amato, M Simona Del Prete,

G Scalise, Institute of Infectious Diseases and Public Health, University of Ancona, Ancona, Italy 
R Ghiselli, F Mocchegiani, V Saba, Department of General Surgery, INRCA IRRCS, University of Ancona, Ancona, Italy

F Orlando, Biotechnology Centre, Research Department, INRCA IRRCS, Ancona, Italy

W Kamysz, J Lukasiak, Faculty of Pharmacy, Medical University of Gdansk, Gdansk, Poland

\section{REFERENCES}

1 Parks RW, Clements WDB, Pope C, et al. Bacterial translocation and gut microflora in obstructive jaundice. J Anat 1996;189:561-5.

2 Clements WDB, Erwin P, McCaigue MD, et al. Conclusive evidence of endotoxaemia in biliary obstruction. Gut 1998:42:293-9.

3 Sewnath ME, Levels HHM, Elferink RO, et al. Endotoxin-induced mortality in bile duct-ligated rats after administration of reconstituted high-density lipoprotein. Hepatology 2000;32:1289-99.

4 Parks RW, Clements WDB, Smye MG, et al. Intestinal barrier dysfunction in clinical and experimental obstructive jaundice and its reversal by internal biliary drainage. Br J Surg 1996:83:1345-9.

5 Deitch EA, Sittig K, Li M, et al. Obstructive jaundice promotes bacterial translocation from the gut. Am J Surg 1990;159:79-84.

6 Berg RD. Bacterial translocation from the gastrointestinal tracts. J Med 1992;23:217-44.

7 Schimpl G, Pesendorfer P, Steinwender G, et al. Allopurinol and glutamine attenuate bacterial translocation in chronic portal hypertensive and common duct ligated growing rats. Gut 1996;39:48-53.

8 Nieuwenhuijs VB, van Dijk JE, Gooszen HG, et al. Ostructive jaundice, bacterial translocation and interdigestive small-bowel motility in rats. Digestion 2000;62:255-61

9 Rosman C, Wübbels GH, Manson WL, et al. Selective decontamination of the digestive tract prevents secondary infection of the abdominal cavity, and endotoxemia and mortality in sterile peritonitis in laboratory ravity, Crit Care Med 1992;20:1699-704.

10 Parks RW, Stuart Cameron CH, Gannon CD, et al. Changes in gastrointestinal morphology associated with obstructive jaundice. J Pathol 2000; 192:526-32

11 Harry D, Anand R, Holt S, et al. Increased sensitivity to endotexemia in the bile-duct- ligated cirrhotic rat. Hepatology 1999:30:1198-205.

12 Kimmings N, Sewnath ME, Mairuhu WM, et al. The abnormal lipid spectrum in malignant obstructive jaundice in relation to endotoxin sensitivity and the result of preoperative biliary drainage. Surgery $2001 ; 129: 282-91$

13 Sewnath ME, van der Poll T, Ten Kate FJ, et al. Interleukin-1 reeceptor type I gene-deficient bile duct-ligated mice are partially protected against endotoxin. Hepatology 2002;35: 149-58

14 Kennedy JA, Lewis H, Clements WDB, et al. Kuppfer cell blockade, tumor necrosis factor secretion and survival following endotoxin challenge in experimental biliary obstruction. $\mathrm{Br} J$ Surg 1999:86:1410-14.
15 Bradfield JWB. Control of spillover: the importance of Kuppfer cell function in clinical medicine. Lancet 1974;ii:883-6.

16 Hardaway RM. A review of septic shock. Am Surg 2000;66:22-9.

17 Bone RC. Pathophysiology of sepsis. Ann Intern Med 1991;115:45769.

18 Bone RC. Gram-negative sepsis: A dilemma of modern medicine. Clin Microbiol Rev 1993;6:57-68

19 Saito JM, Maher JJ. Bile duct ligation in rats induces biliary expression of cytokine- induced neutrophil chemoattractant. Gastroenterology 2000; 118:1 157-68.

20 Wheeler AP, Bernard GR. Treating patients with severe sepsis. N Engl J Med 1999:340:207-14.

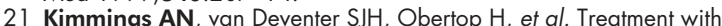
recombinant bactericidal/permeability-increasing protein to prevent endotoxin-induced mortality in bile duct-ligated rats. J Am Coll Surg 1999; 189:374-9

22 Hancock REW, Chapple DS. Peptide antibiotics. Antimicrob Agents Chemother 1999;43:1317-23.

23 Hancock REW, Scott MG. The role of antimicrobial peptides in animal defenses. Proc Natl Acad Sci U S A 2000; 97:856-61.

24 Cho Y, Turner JS, Dinh NN, et al. Activity of protegrins against yeast-phase Candida albicans. Infect Immun 1998:66:2486-93.

25 Chen J, Falla TJ, Liu H, et al. Development of protegrins for the treatment and prevention of oral mucositis: structure-activity relationships of synthetic protegrin analogues. Biopolymers 2000;55:88-98.

26 Mosca DA, Hurst MA, So W, et al. IB-367, a protegrin peptide with in vitro and in vivo activities against the microflora associated with oral mucositis. Antimicrob Agents Chemother 2000;44:1803-8.

27 Falla TJ, Hancock REW. Improved activity of a synthetic indolicidin analog. Antimicrob Agents Chemother 1997:41:771-5.

28 Gough M, Hancock REW, Kelly NM. Antiendotoxin activity of cationic peptide antimicrobial agents. Infect Immun 1996;64:4922-7.

29 Hancock REW. Therapeutic potential of cationic peptides. Expert Opin Investig Dis 1998;7:167-74

30 Cirioni O, Giacometti A, Ghiselli R, et al. Single-dose intraperitoneal magainins improve survival in a gram-negative-pathogens septic shock rat model. Antimicrob Agents Chemother 2002;46:101-4.

31 Giacometti A Cirioni O, Ghiselli R, et al. Potential therapeutic role of cationic peptides in three experimental models of septic shock. Antimicrob Agents Chemother 2002;46:2132-6.

32 Kamysz W, Kochañska B, Kêdzia A, et al. Statherin SV2 and its analogue. Synthesis and evaluation of antimicrobial activity. Polish Chem 2002;76:801-6.

33 Reynolds JV, Murchan P, Redmond HP, et al. Failure of macrophage activation in experimental obstructive jaundice: association with bacterial translocation. Br J Surg 1995:82:534-8.

34 Grinko I, Geerts A, Wisse E. Experimental biliary fibrosis correlates with increased numbers of fat-storing and Kupffer cells, and portal endotoxemia. J Hepatol 1995;23:449-58.

35 Scott MG, Yan H, Hancock REW. Biological properties of structurally related $\alpha$ - helical cationic antimicrobial peptides. Infect Immun 1999:67:2005-9. 